\title{
Molecular Approaches to the Treatment, Prophylaxis, and Diagnosis of Alzheimer's Disease: Endoplasmic Reticulum Stress and Immunological Stress in Pathogenesis of Alzheimer's Disease
}

\author{
Toru Hosoi ${ }^{1, * a}$ and Koichiro Ozawa ${ }^{1, * b}$ \\ ${ }^{1}$ Department of Pharmacotherapy, Graduate School of Biomedical Sciences, Hiroshima University, \\ 1-2-3 Kasumi, Minami-ku, Hiroshima 734-8551, Japan
}

Received October 15, 2011; Accepted December 15, 2011

\begin{abstract}
Alzheimer's disease (AD) is an age-related neurodegenerative disorder, accompanied by neuronal loss and the formation of senile plaques in the brain. Glial cells, such as microglia, have been shown to be activated and induce chronic inflammatory responses in AD brain. The endoplasmic reticulum (ER) functions to facilitate protein folding. However, ER stress occurs when cells are exposed to stress. Mounting evidence suggests that ER stress is involved in the pathology of AD. Meanwhile, recent findings suggested crosstalk between ER stress and immune function. However, the mechanisms linking the progression of AD with ER and immunological stress are still not clear. In the present paper, we review and discuss recent results regarding the mechanism of $\mathrm{AD}$ pathogenesis, focusing on ER stress and immunological stress.
\end{abstract}

Keywords: endoplasmic reticulum stress, inflammation, glial cell, neuron, Alzheimer's disease

\section{Introduction}

Alzheimer's disease (AD) is characterized by a decline in cognitive function (1), which is accompanied by neuronal loss and senile plaques in the brain. In addition to these hallmarks, new diagnostic method for imaging $\mathrm{AD}$ pathology using novel PET/SPECT probes has been recently developed (for details, see the article written by Ono and Saji in this Forum Minireview series: Ref. 2). Neuropathological analyses of AD brain suggest one of the major causes of AD to be the accumulation of amyloid $\beta$-peptide in cerebral neuritic plaques. The build-up of amyloid $\beta$-peptide has been suggested to activate glial cells, such as microglia and astrocytes (for details, see the article written by Takata and Kitamura in this Forum Minireview series: Ref. 3), which subsequently activate immune reactions. Moreover, increase in amyloid $\beta$-peptide would result in neuronal cell death in the affected areas. Interestingly, cell death has been suggested

Corresponding authors.

*atoruh@hiroshima-u.ac.jp, *bozawak@hiroshima-u.ac.jp

Published online in J-STAGE on March 2, 2012 (in advance)

doi: 10.1254/jphs.11R09FM to accompany endoplasmic reticulum (ER) stress $(4,5)$. The ER is an organelle that functions to facilitate protein folding. However, exposure to stress results in loss of function and causes ER stress. Intriguingly, crosstalk between ER stress and immune function has been suggested $(6-11)$. Therefore, elucidation of the mechanisms of ER stress and immune function activated in AD brain may provide beneficial information for the pharmacological treatment of AD. Thus, in this review, we describe basic mechanisms of ER and immunological stress and discuss the therapeutic opportunities for AD.

\section{ER stress}

The accumulation of unfolded or misfolded proteins in the ER triggers ER stress. Cells counteract the stress by activating several sensor proteins located in the ER (Fig. $1)$. This process is known as the unfolded protein response (UPR). Activation of UPR alleviates ER stress by 1 ) increasing the folding capacity of unfolded or misfolded proteins, 2) inhibiting general protein translation, and 3 ) promoting the degradation of unfolded or misfolded proteins $(12-14)$. In addition, unfolded or misfolded proteins in the ER are retrogradely transported 


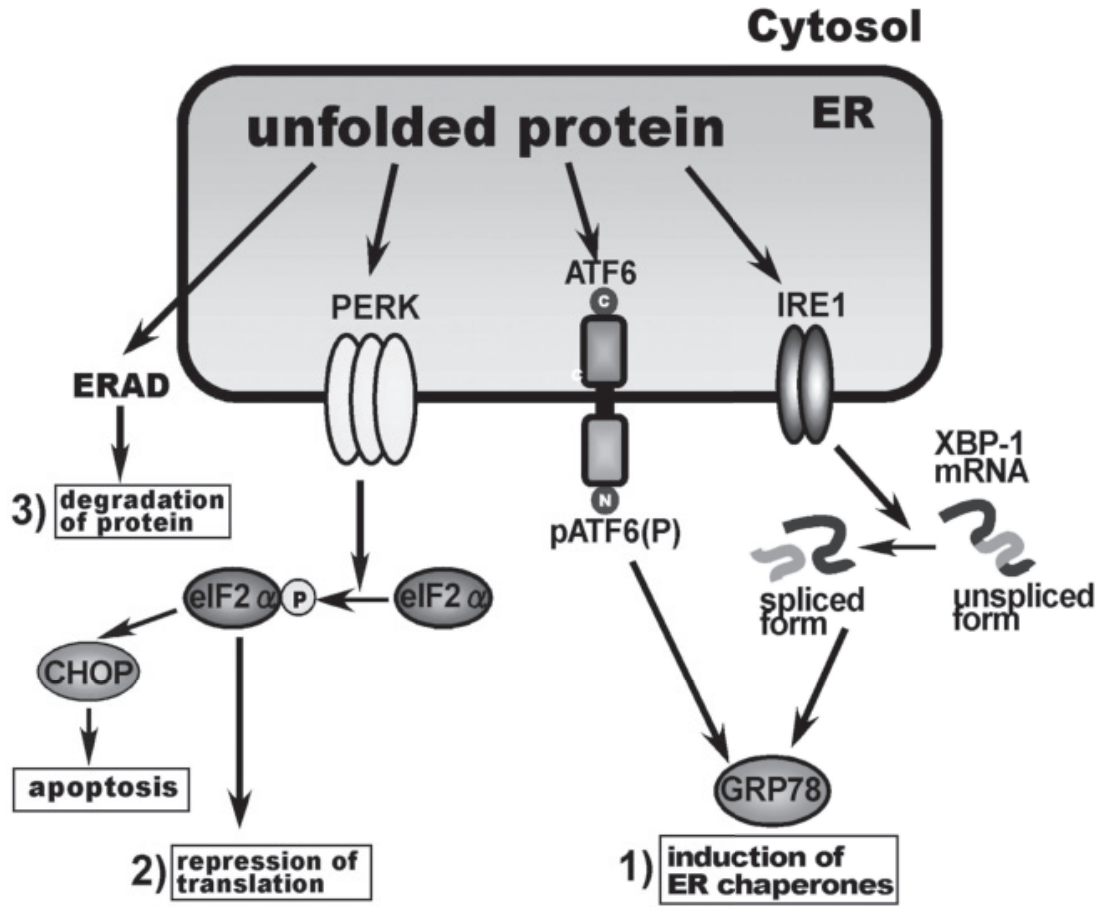

Fig. 1. Mechanisms of the integrative signaling response to ER stress. Upon ER stress, several ER-localized stress-sensor proteins are activated, which subsequently induces a subset of ER stressregulated genes. In addition, ER stress promotes the degradation of unfolded or misfolded proteins. from the ER to the cytoplasm through translocons, which are then degraded by the ubiquitin-proteasome system (for details, see the article written by Kaneko et al. in this Forum Minireview series: Ref. 15) $(16,17)$. On the other hand, when exposed to stronger or prolonged stress, which cells by themselves cannot withstand, cells will eventually undergo apoptosis through the activation of ER-specific caspases $(18,19)$ or apoptotic transcription factors, such as CCAAT/enhancer-binding protein homologous protein (CHOP) $(20,21)$.

Three major types of ER-resident proteins have been identified as sensors for ER stress: that is, inositol-requiring protein-1 (IRE1), PKR-like ER kinase (PERK), and activating transcription factor 6 (ATF6). When these stress-sensor proteins are activated through the sensing of unfolded proteins in the ER, it will eventually transmit the signals to nucleus and increases a subset of specific genes to accommodate such stress (22).

Activation of IRE1 induces X-box binding protein 1 (XBP-1) mRNA splicing by cleaving off its intron (23). Spliced XBP-1 then functions as a transcription factor specific for ER stress-related genes (24).

Activation of PERK phosphorylates the $\alpha$-subunit of eukaryotic translation initiation factor 2 (eIF2), which results in translational repression $(25,26)$. eIF2 phosphorylation, however, promotes the translation of activating transcription factor 4 (ATF4), which subsequently produces CHOP protein, an apoptotic transcription factor (27).
Activation of ATF6 is mediated through regulated intramembrane proteolysis (RIP), which involves translocation from the ER to the Golgi complex, the site where it is cleaved by Golgi-resident serine proteases, site 1 protease (S1P), and site 2 protease (S2P) $(28,29)$. The cleaved $50-\mathrm{kDa}$ cytoplasmic basic-leucine zipper (bZIP)-containing fragment then activates the transcription of UPR target genes.

\section{Alzheimer's disease and ER stress}

$\mathrm{AD}$ is characterized by an accumulation of unfolded or misfolded proteins in the brain. Several reports indicate the activation of UPR in AD brain (30 - 32), suggesting a possible link between AD and ER stress. One of the proposed mechanisms of $\mathrm{AD}$ progression is the accumulation of amyloid $\beta$-peptide in cerebral neuritic plaques. Amyloid $\beta$ activates UPR signaling such as PERK or XBP-1 splicing, which in turn is suggested to prevent amyloid $\beta$ neurotoxicity $(33,34)$. Amyloid $\beta$-peptide is generated by cleavage of amyloid precursor protein (APP). Presenilin-1 (PS1) and $\beta$-site APP cleaving enzyme-1 (BACE1) are important components of $\gamma$-secretase- and $\beta$-secretase-mediated cleavage of APP, respectively. Several types of familial gene variations have been suggested to be linked with AD pathology (for details, see the article written by Shoji in this Forum Minireview series: Ref. 35). Interestingly, a familial ADlinked PS1 mutation has been shown to be associated 
with ER stress (36), and eIF2 $\alpha$ phosphorylation was shown to increase BACE1 levels (37). Moreover, amyloid $\beta$-peptide-induced neuronal cell death was mediated through ER stress-specific mouse caspase-12 (18) or human caspase-4 (19). In addition, $S$-nitrosylation of protein-disulphide isomerase (PDI), an ER-localized protein involved in disulfide bonds, was reported to be involved in protein misfolding and neurodegeneration in cases of sporadic AD (38). PDI has been suggested to attenuate protein misfolding in neurodegenerative disease. In this report, they suggested that formation of $S$ nitrosylated PDI (SNO-PDI) would cause malfunction of PDI, which would result in neurodegenerative disease. As nitric oxide (NO) is involved in AD progression (39), the linkage of NO and ER stress on the development of sporadic AD would be a mechanism involved. On the other hand, an alternatively spliced form of the PS2 gene, which lacks exon 5 (PS2V), has been reported to be expressed in sporadic AD brains (40), and the cells expressing PS2V were found to be more susceptible to ER stresses (41). Therefore, the linkage between PS2V and ER stress would be one of the causal factors for sporadic AD. Previously, we reported that serine/threonine kinase Akt, a downstream target of PI3K, is regulated by ER stress in glial cells (42). We found that Akt expression was transiently up-regulated, but down-regulated in response to ER stress. In addition, one possible mechanism of Akt regulation would be through TEK/Tie2 expression because the levels were regulated by ER stress (43). Increased activation of Akt was observed in AD brains (44 - 46). Meanwhile, weak activation of Akt was found in terminally degenerated $\mathrm{AD}$ neurons (46). PI3K/Akt signaling regulates cell survival. Indeed, deactivation of Akt in ER-stressed cells caused cell death $(47,48)$. Therefore, ER stress would regulate the activation status of Akt, which may be linked with the neurodegeneration observed in AD.

Overall, these molecular and pathological findings suggest that ER stress may be involved in the progression of $\mathrm{AD}$.

\section{Crosstalk between ER stress and immunological stress}

In addition to ER stress, inflammatory genes are upregulated in $\mathrm{AD}$ brain. Moreover, it is believed that inflammatory processes are involved in the development of sporadic AD (49). Therefore, chronic inflammatory conditions would contribute to the disease. Emerging evidence suggests that in addition to neuronal cells, glial cells such as microglia and astrocytes participate in $\mathrm{AD}$ progression. For example, amyloid $\beta$ accumulation activates glial cells, which subsequently produce pro-inflam- matory cytokines and inducible nitric oxide synthase (iNOS) $(50-52)$. These inflammatory responses in the glial cells in turn affect neuronal cell fate. Therefore, it is possible that such neuro-glial crosstalk would contribute to AD. On the other hand, the existence of crosstalk between ER stress and immune function has been suggested $(6-11)$. The transcription factor XBP-1 has been reported to induce interleukin (IL)-6 expression in B cells (6), and ER stress elicited an acute inflammatory response through the liver-specific transcription factor CREBH (9). Meanwhile, ER stress-induced CHOP expression was suppressed by prior activation of toll-like receptor (TLR) 3 or 4, which recognizes specific molecular patterns of microbial components (10). Conversely, activation of the immune system has been shown to increase UPR. Lipopolysaccharide (LPS), a Gram-negative bacterial cell wall component, induced the UPR-regulated expression of genes such as CHOP in lung (7). Moreover, TLR activated IRE1 $\alpha$-XBP1 signaling and TLR-activated XBP1 was required for optimal and sustained production of pro-inflammatory cytokines in macrophages (11). In addition, the pro-inflammatory cytokine tumor necrosis factor $\alpha(\mathrm{TNF} \alpha)$ itself has been shown to induce UPR (8) and interferon- $\gamma$-induced apoptosis of oligodendrocytes was mediated through ER stress (53).

Overall, taking into account the functional crosstalk between ER stress and immune function, these factors may play key roles in the progression of AD. However, it is not clear whether ER stress-immune crosstalk is observed in the AD brain.

\section{Concluding remarks}

In recent years, research into the basic mechanisms of UPR and ER stress-related diseases has progressed rapidly. Importantly, in addition to AD, involvement of ER stress in Parkinson's disease, cerebral ischemic insult, cancer, obesity, and diabetes has been suggested. These observations open possibilities for developing novel therapeutic compounds that can ameliorate ER stress. Indeed, there have been reports of several compounds that can target ER stress-regulated proteins such as eIF $2 \alpha$ (54), IRE1 (55 - 57), and GRP78 (58). In addition, small molecules known as chemical chaperones, which inhibit the aggregation of proteins, were shown to be effective in reducing ER stress and ameliorating Parkinson's disease (59), diabetes (60), and obesity $(61,62)$.

Epidemiological evidence suggests that non-steroidal anti-inflammatory drugs (NSAIDs) would be useful for treating AD (63). The pharmacological action of NSAIDs against $\mathrm{AD}$ would be mediated by attenuating inflammation. Intriguingly, some NSAIDs were shown to modulate ER stress in neuronal (64) as well as glial cells (65). 
These results raise the possibility that several NSAIDs may have unique pharmacological properties in regulating ER stress. Therefore, we speculate that the multifunctional properties of NSAIDs, that is, attenuating ER stress as well as immunological stress, would result in beneficial effects in attenuating AD. However, these possibilities require further analysis.

In addition to regulating ER stress, several reports suggest the physiological role of each component of UPR. It is suggested that each branch of the UPR components have a diverse and specific role for the normal functions of cellular homeostasis $(66-70)$. Therefore, NSAIDs as well as compounds that can regulate ER stress by regulating UPR would affect basal physiologic actions. Such a pharmacological action may, in turn, cause side effects. Thus, special attention is required for discovery and use of new drugs targeting UPR.

Although pharmacological research into ER stress is still in its infancy, we believe that analyzing the mechanisms involved and identifying compounds directed against ER stress will provide new avenues for treating $\mathrm{AD}$.

\section{Acknowledgments}

The authors thank Dr. Yasuyuki Nomura (Yokohama College of Pharmacy, Yokohama) and Dr. Yasunobu Okuma (Chiba Institute of Science, Choshi) for their helpful discussions. The present study was supported by Grants-in-Aid for Scientific Research from the Ministry of Education, Culture, Sports, Science, and Technology, Japan and by the Takeda Science Foundation.

\section{References}

1 Selkoe DJ. Alzheimer's disease: genes, proteins, and therapy. Physiol Rev. 2001;81:741-766.

2 Ono M, Saji H. Molecular approaches to the treatment, prophylaxis, and diagnosis of Alzheimer's disease: Novel PET/SPECT imaging probes for diagnosis of Alzheimer's disease. J Pharmacol Sci. 2012;118:338-344.

3 Takata K, Kitamura Y. Molecular approaches to the treatment, prophylaxis, and diagnosis of Alzheimer's disease: Tangle formation, amyloid- $\beta$, and microglia in Alzheimer's disease. J Pharmacol Sci. 2012;118:331-337.

4 Imaizumi K, Miyoshi K, Katayama T, Yoneda T, Taniguchi M, Kudo T, et al. The unfolded protein response and Alzheimer's disease. Biochim Biophys Acta. 2001;1536:85-96.

5 Lindholm D, Wootz H, Korhonen L. ER stress and neurodegenerative diseases. Cell Death Differ. 2006;13:385-392.

6 Iwakoshi NN, Lee AH, Vallabhajosyula P, Otipoby KL, Rajewsky $\mathrm{K}$, Glimcher LH. Plasma cell differentiation and the unfolded protein response intersect at the transcription factor XBP-1. Nat Immunol. 2003;4:321-329.

7 Endo M, Oyadomari S, Suga M, Mori M, Gotoh T. The ER stress pathway involving CHOP is activated in the lungs of LPS-treated mice. J Biochem. 2005;138:501-507.

8 Xue X, Piao JH, Nakajima A, Sakon-Komazawa S, Kojima Y,
Mori K, et al. Tumor necrosis factor $\alpha$ (TNF $\alpha$ ) induces the unfolded protein response (UPR) in a reactive oxygen species (ROS)-dependent fashion, and the UPR counteracts ROS accumulation by TNF $\alpha$. J Biol Chem. 2005;280:33917-33925.

9 Zhang K, Shen X, Wu J, Sakaki K, Saunders T, Rutkowski DT, et al. Endoplasmic reticulum stress activates cleavage of CREBH to induce a systemic inflammatory response. Cell. 2006;124: 587-599.

10 Woo CW, Cui D, Arellano J, Dorweiler B, Harding H, Fitzgerald $\mathrm{KA}$, et al. Adaptive suppression of the ATF4-CHOP branch of the unfolded protein response by toll-like receptor signalling. Nat Cell Biol. 2009;11:1473-1480.

11 Martinon F, Chen X, Lee AH, Glimcher LH. TLR activation of the transcription factor XBP1 regulates innate immune responses in macrophages. Nat Immunol. 2010;11:411-418.

12 Mori K. Tripartite management of unfolded proteins in the endoplasmic reticulum. Cell. 2000;101:451-454.

13 Ron D, Walter P. Signal integration in the endoplasmic reticulum unfolded protein response. Nat Rev Mol Cell Biol. 2007;8: 519-529.

14 Hosoi T, Ozawa K. Endoplasmic reticulum stress in disease: mechanisms and therapeutic opportunities. Clin Sci (Lond). 2010;118:19-29.

15 Kaneko M, Okuma Y, Nomura Y. Molecular approaches to the treatment, prophylaxis, and diagnosis of Alzheimer's disease: Possible involvement of HRD1, a novel molecule related to endoplasmic reticulum stress, in Alzheimer's disease. J Pharmacol Sci. 2012;118:325-330.

16 Hampton RY. ER-associated degradation in protein quality control and cellular regulation. Curr Opin Cell Biol. 2002;14: 476-482.

17 Kaneko M, Koike H, Saito R, Kitamura Y, Okuma Y, Nomura Y. Loss of HRD1-mediated protein degradation causes amyloid precursor protein accumulation and amyloid-beta generation. J Neurosci. 2010;30:3924-3932.

18 Nakagawa T, Zhu H, Morishima N, Li E, Xu J, Yankner BA, et al. Caspase-12 mediates endoplasmic-reticulum-specific apoptosis and cytotoxicity by amyloid- $\beta$. Nature. 2000;403: 98-103.

19 Hitomi J, Katayama T, Eguchi Y, Kudo T, Taniguchi M, Koyama $\mathrm{Y}$, et al. Involvement of caspase-4 in endoplasmic reticulum stress-induced apoptosis and Abeta-induced cell death. J Cell Biol. 2004;165:347-356.

20 Wang XZ, Lawson B, Brewer JW, Zinszner H, Sanjay A, Mi LJ, et al. Signals from the stressed endoplasmic reticulum induce C/ EBP-homologous protein (CHOP/GADD153). Mol Cell Biol. 1996;16:4273-4280.

21 Zinszner H, Kuroda M, Wang X, Batchvarova N, Lightfoot RT, Remotti H, et al. CHOP is implicated in programmed cell death in response to impaired function of the endoplasmic reticulum. Genes Dev. 1998;12:982-995.

22 Kaufman RJ. Stress signaling from the lumen of the endoplasmic reticulum: coordination of gene transcriptional and translational controls. Genes Dev. 1999;13:1211-1233.

23 Calfon M, Zeng H, Urano F, Till JH, Hubbard SR, Harding HP, et al. IRE1 couples endoplasmic reticulum load to secretory capacity by processing the XBP-1 mRNA. Nature. 2002;415: 92-96.

24 Lee AH, Iwakoshi NN, Glimcher LH. XBP-1 regulates a subset of endoplasmic reticulum resident chaperone genes in the un- 
folded protein response. Mol Cell Biol. 2003;23:7448-7459.

25 Shi Y, Vattem KM, Sood R, An J, Liang J, Stramm L, et al. Identification and characterization of pancreatic eukaryotic initiation factor $2 \alpha$-subunit kinase, PEK, involved in translational control. Mol Cell Biol. 1998;18:7499-7509.

26 Harding HP, Zhang Y, Ron D. Protein translation and folding are coupled by an endoplasmic-reticulum-resident kinase. Nature. 1999;397:271-274.

27 Harding HP, Novoa I, Zhang Y, Zeng H, Wek RC, Schapira M, et al. Regulated translation initiation controls stress-induced gene expression in mammalian cells. Mol Cell. 2000;6:1099-1108.

28 Shen J, Chen X, Hendershot L, Prywes R. ER stress regulation of ATF6 localization by dissociation of BiP/GRP78 binding and unmasking of Golgi localization signals. Dev Cell. 2002;3: 99-111.

29 Haze K, Yoshida H, Yanagi H, Yura T, Mori K. Mammalian transcription factor ATF6 is synthesized as a transmembrane protein and activated by proteolysis in response to endoplasmic reticulum stress. Mol Biol Cell. 1999;10:3787-3799.

30 Hoozemans JJ, Veerhuis R, Van Haastert ES, Rozemuller JM, Baas F, Eikelenboom P, et al. The unfolded protein response is activated in Alzheimer's disease. Acta Neuropathol. 2005;110: 165-172.

31 Unterberger U, Höftberger R, Gelpi E, Flicker H, Budka H, Voigtländer T. Endoplasmic reticulum stress features are prominent in Alzheimer disease but not in prion diseases in vivo. $\mathrm{J}$ Neuropathol Exp Neurol. 2006;65:348-357.

32 Hoozemans JJ, van Haastert ES, Nijholt DA, Rozemuller AJ, Eikelenboom P, Scheper W. The unfolded protein response is activated in pretangle neurons in Alzheimer's disease hippocampus. Am J Pathol. 2009;174:1241-1251.

33 Lee DY, Lee KS, Lee HJ, Kim DH, Noh YH, Yu K, et al. Activation of PERK signaling attenuates $\mathrm{A} \beta$-mediated ER stress. PLoS One. 2010;5:e10489.

34 Casas-Tinto S, Zhang Y, Sanchez-Garcia J, Gomez-Velazquez M, Rincon-Limas DE, Fernandez-Funez P. The ER stress factor XBP1s prevents amyloid- $\beta$ neurotoxicity. Hum Mol Genet. 2011;20:2144-2160.

35 Shoji M. Molecular approaches to the treatment, prophylaxis, and diagnosis of Alzheimer's disease: Clinical molecular and genetic studies on Alzheimer's disease. J Pharmacol Sci. 2012; 118:345-349.

36 Katayama T, Imaizumi K, Sato N, Miyoshi K, Kudo T, Hitomi J, et al. Presenilin-1 mutations downregulate the signalling pathway of the unfolded-protein response. Nat Cell Biol. 1999;1: 479-485.

37 O'Connor T, Sadleir KR, Maus E, Velliquette RA, Zhao J, Cole $\mathrm{SL}$, et al. Phosphorylation of the translation initiation factor eIF2 $\alpha$ increases BACE1 levels and promotes amyloidogenesis. Neuron. 2008;60:988-1009.

38 Uehara T, Nakamura T, Yao D, Shi ZQ, Gu Z, Ma Y, et al. SNitrosylated protein-disulphide isomerase links protein misfolding to neurodegeneration. Nature. 2006;441:513-517.

39 Law A, Gauthier S, Quirion R. Say NO to Alzheimer's disease: the putative links between nitric oxide and dementia of the Alzheimer's type. Brain Res Brain Res Rev. 2001;35:73-96.

40 Sato N, Hori O, Yamaguchi A, Lambert JC, Chartier-Harlin MC, Robinson PA, et al. A novel presenilin-2 splice variant in human Alzheimer's disease brain tissue. J Neurochem. 1999;72:24982505 .
41 Sato N, Imaizumi K, Manabe T, Taniguchi M, Hitomi J, Katayama $\mathrm{T}$, et al. Increased production of $\beta$-amyloid and vulnerability to endoplasmic reticulum stress by an aberrant spliced form of presenilin 2. J Biol Chem. 2001;276:2108-2114.

42 Hosoi T, Hyoda K, Okuma Y, Nomura Y, Ozawa K. Akt up- and down-regulation in response to endoplasmic reticulum stress. Brain Res. 2007;1152:27-31.

43 Hosoi T, Tamubo T, Horie N, Okuma Y, Nomura Y, Ozawa K. TEK/Tie2 is a novel gene involved in endoplasmic reticulum stress. J Pharmacol Sci. 2010;114:230-233.

44 Griffin RJ, Moloney A, Kelliher M, Johnston JA, Ravid R, Dockery $\mathrm{P}$, et al. Activation of Akt/PKB, increased phosphorylation of Akt substrates and loss and altered distribution of Akt and PTEN are features of Alzheimer's disease pathology. J Neurochem. 2005;93:105-117.

45 Pei JJ, Khatoon S, An WL, Nordlinder M, Tanaka T, Braak H, et al. Role of protein kinase B in Alzheimer's neurofibrillary pathology. Acta Neuropathol (Berl). 2003;105:381-392.

46 Rickle A, Bogdanovic N, Volkman I, Winblad B, Ravid R, Cowburn RF. Akt activity in Alzheimer's disease and other neurodegenerative disorders. Neuroreport. 2004;15:955-959.

47 Srinivasan S, Ohsugi M, Liu Z, Fatrai S, Bernal-Mizrachi E, Permutt MA. Endoplasmic reticulum stress-induced apoptosis is partly mediated by reduced insulin signaling through phosphatidylinositol 3-kinase/Akt and increased glycogen synthase kinase3b in mouse insulinoma cells. Diabetes. 2005;54:968-975.

48 Hyoda K, Hosoi T, Horie N, Okuma Y, Ozawa K, Nomura Y. PI3K-Akt inactivation induced CHOP expression in endoplasmic reticulum-stressed cells. Biochem Biophys Res Commun. 2006; 340:286-290.

49 McGeer EG, McGeer PL. Inflammatory processes in Alzheimer's disease. Prog Neuropsychopharmacol Biol Psychiatry. 2003; 27:741-749.

50 Meda L, Cassatella MA, Szendrei GI, Otvos L Jr, Baron P, Villalba M, et al. Activation of microglial cells by beta-amyloid protein and interferon-gamma. Nature. 1995;374:647-650.

51 Akama KT, Albanese C, Pestell RG, Van Eldik LJ. Amyloid $\beta$-peptide stimulates nitric oxide production in astrocytes through an NF $\kappa$ B-dependent mechanism. Proc Natl Acad Sci U S A. 1998;95:5795-5800.

52 Nomura J, Hosoi T, Okuma Y, Nomura Y. A beta-induced TNF- $\alpha$ expression and acetylcholine action in mouse glial cells. Life Sci. 2003;72:2117-2120.

53 Lin W, Harding HP, Ron D, Popko B. Endoplasmic reticulum stress modulates the response of myelinating oligodendrocytes to the immune cytokine interferon-gamma. J Cell Biol. 2005;169: 603-612.

54 Boyce M, Bryant KF, Jousse C, Long K, Harding HP, Scheuner $\mathrm{D}$, et al. A selective inhibitor of eIF $2 \alpha$ dephosphorylation protects cells from ER stress. Science. 2005;307:935-939.

55 Wiseman RL, Zhang Y, Lee KP, Harding HP, Haynes CM, Price $\mathrm{J}$, et al. Flavonol activation defines an unanticipated ligandbinding site in the kinase-RNase domain of IRE1. Mol Cell. 2010;38:291-293.

56 Papandreou I, Denko NC, Olson M, Van Melckebeke H, Lust S, Tam A, et al. Identification of an Ire1alpha endonuclease specific inhibitor with cytotoxic activity against human multiple myeloma. Blood. 2011;117:1311-1314.

57 Volkmann K, Lucas JL, Vuga D, Wang X, Brumm D, Stiles C, et al. Potent and selective inhibitors of the inositol-requiring 
enzyme 1 endoribonuclease. J Biol Chem. 2011;286:1274312755.

58 Kudo T, Kanemoto S, Hara H, Morimoto N, Morihara T, Kimura $\mathrm{R}$, et al. A molecular chaperone inducer protects neurons from ER stress. Cell Death Differ. 2008;15:364-375.

59 Kubota K, Niinuma Y, Kaneko M, Okuma Y, Sugai M, Omura T, et al. Suppressive effects of 4-phenylbutyrate on the aggregation of Pael receptors and endoplasmic reticulum stress. J Neurochem. 2006;97:1259-1268.

60 Ozcan U, Yilmaz E, Ozcan L, Furuhashi M, Vaillancourt E, Smith RO, et al. Chemical chaperones reduce ER stress and restore glucose homeostasis in a mouse model of type 2 diabetes. Science. 2006;313:1137-1140.

61 Hosoi T, Sasaki M, Miyahara T, Hashimoto C, Matsuo S, Yoshii $\mathrm{M}$, et al. Endoplasmic reticulum stress induces leptin resistance. Mol Pharmacol. 2008;74:1610-1619.

62 Ozcan L, Ergin AS, Lu A, Chung J, Sarkar S, Nie D, et al. Endoplasmic reticulum stress plays a central role in development of leptin resistance. Cell Metab. 2009;9:35-51.

63 in 't Veld BA, Ruitenberg A, Hofman A, Launer LJ, van Duijn $\mathrm{CM}$, Stijnen T, et al. Nonsteroidal antiinflammatory drugs and the risk of Alzheimer's disease. N Engl J Med. 2001;345: 1515-1521.

64 Yamazaki T, Muramoto M, Oe T, Morikawa N, Okitsu O,
Nagashima T, et al. Diclofenac, a non-steroidal anti-inflammatory drug, suppresses apoptosis induced by endoplasmic reticulum stresses by inhibiting caspase signaling. Neuropharmacology. 2006;50:558-567.

65 Hosoi T, Sasaki M, Baba S, Ozawa K. Effect of pranoprofen on endoplasmic reticulum stress in the primary cultured glial cells. Neurochem Int. 2009;54:1-6.

$66 \mathrm{Wu}$ J, Kaufman RJ. From acute ER stress to physiological roles of the unfolded protein response. Cell Death Differ. 2006;13: 374-384.

67 Lee AH, Glimcher LH. Intersection of the unfolded protein response and hepatic lipid metabolism. Cell Mol Life Sci. 2009;66:2835-2850.

68 Rutkowski DT, Hegde RS. Regulation of basal cellular physiology by the homeostatic unfolded protein response. J Cell Biol. 2010;189:783-794.

69 Hetz C, Martinon F, Rodriguez D, Glimcher LH. The unfolded protein response: integrating stress signals through the stress sensor IRE1 $\alpha$. Physiol Rev. 2011;91:1219-1243.

70 Kondo S, Saito A, Asada R, Kanemoto S, Imaizumi K. Physiological unfolded protein response regulated by OASIS family members, transmembrane bZIP transcription factors. IUBMB Life. 2011;63:233-239. 